\title{
Efficient Adsorption of Hydrogen Sulfide at Room Temperature Using Fumed Silica-supported Deep Eutectic Solvents
}

\author{
Jiaming Mao ${ }^{1}$, Yunqian Ma ${ }^{1,2^{*}}$, Lihua Zang ${ }^{1^{* *}}$, Rong Xue ${ }^{1}$, Cong Xiao ${ }^{3}$, Dandan $\mathrm{Ji}^{1,2,4}$ \\ ${ }^{1}$ College of Environmental Science and Engineering, Qilu University of Technology (Shandong Academy of Science), \\ Jinan 250353, China \\ ${ }^{2}$ Jiangsu Key Laboratory of Anaerobic Biotechnology (Jiangnan University), Wuxi 214122, China \\ ${ }^{3}$ Shandong Huacheng Construction Design and Engineering Co., Ltd., Jinan 250301, China \\ ${ }^{4}$ Huatai Group, Guangrao 257335, China
}

\begin{abstract}
Supported deep eutectic solvents (SDESs) using fumed silica as the supporting material and $\mathrm{TAECuCl}_{3}$ as the loading substance, were developed for $\mathrm{H}_{2} \mathrm{~S}$ removal. The highest breakthrough sulfur capacity, $9.97 \mathrm{mg} \mathrm{g}^{-1}$, was achieved when the molar ratio of the TEACl to the $\mathrm{CuCl}_{2}$ was $1: 1$, the loading rate of the DES was $10 \%$, and the temperature was $30^{\circ} \mathrm{C}$. $\mathrm{TAECuCl}_{3}$ proved to be a more effective loading substance than pure TEACl, pure $\mathrm{CuCl}_{2}$, or blends of these substances at other ratios. Due to the high utilization rates of the metal-activated sites, the SDESs were more economical. The excellent capacity for $\mathrm{H}_{2} \mathrm{~S}$ removal was attributable to the formation of a thin layer of DES, nano-sized in thickness, on the fumed silica. The XRD and XPS analysis showed that the products of desulfurization were $\mathrm{S}$ and $\mathrm{Cu}_{2} \mathrm{~S}$, the latter of which was then oxidized to $\mathrm{S}$ and $\mathrm{SO}_{4}{ }^{2-}$ by air at room temperature. After regenerating 4 times, the breakthrough sulfur capacity of the SDESs was still as high as $7.39 \mathrm{mg} \mathrm{g}^{-1}$. The nonlinear curve fitting demonstrated that the adsorption kinetics followed those of the Bangham kinetic model.
\end{abstract}

Keywords: Hydrogen sulfide; Adsorption; Fumed silica; Deep eutectic solvents.

\section{INTRODUCTION}

It is well known that hydrogen sulfide $\left(\mathrm{H}_{2} \mathrm{~S}\right)$ and other sulfur-containing compounds found in industrially important hydrocarbon feedstock have severe negative impact on human beings and the ecosystem in general (Montes et al., 2013). These sulfuric compounds can increase corrosion in process equipment, and lead to the deactivation of catalysts and environmental threat in end-use upon combustion (Liu and Wang, 2017; Ma et al., 2017). $\mathrm{H}_{2} \mathrm{~S}$ can cause various respiratory symptoms, even death at a low level (10-500 ppmv) (Yang et al., 2006). Up to now, many technologies such as gas-liquid absorption, adsorption or biological process are used to remove $\mathrm{H}_{2} \mathrm{~S}$. Nevertheless, the gas-liquid absorption process with an aqueous solution of ammonia, alkanolamine or alkaline salts suffers from the drawbacks of foaming,

\footnotetext{
* Corresponding author.

Tel.: +86 531 89631680; Fax: +8653189631680

E-mail address: yqma_1986@163.com

** Corresponding author.

Tel.: +86 531 89631680; Fax: +86 53189631680

E-mail address: ZLH@qlu.edu.cn
}

inapplicability for high temperature and requiring high energy consumption for the regeneration (Ma and Wang, 2014a). Although biological process could efficiently remove $\mathrm{H}_{2} \mathrm{~S}$, it costs much time and is inefficient with $\mathrm{H}_{2} \mathrm{~S}$ of high concentration. Adsorption by metal oxides, activated carbon, zeolite or silica which is recognized to be an efficient technology for $\mathrm{H}_{2} \mathrm{~S}$ removal at high temperature, but requires a stable support with a high adsorption capacity and selectivity towards $\mathrm{H}_{2} \mathrm{~S}$ gas.

In order to solve the aforementioned drawbacks, ionic liquids (ILs) have been widely studied for $\mathrm{H}_{2} \mathrm{~S}$ absorption and oxidation due to their extremely low vapor pressures, high thermostability, and tunable chemical structures (Welton, 1999; Fukumoto et al., 2005). In wet desulfurization, the wide interest in ILs arises from a general need for environmentally friendly, new green solvents to replace water, which present the problem of high volatility at high temperature (Liu and Wang, 2016). Especially, enhanced absorption of $\mathrm{H}_{2} \mathrm{~S}$ into functionalized ILs, such as amino-based, metal-based (Ma and Wang, 2014b), substituted benzoate-based and pyridiniumbased ILs (Huang et al., 2016a), is an attractive approach that exhibits benign $\mathrm{H}_{2} \mathrm{~S}$ removal capacities. However, the drawbacks of these ILs, such as high viscosity, complicated synthesis and high costs, may limit their large-scale application. The viscosity of $\mathrm{H}_{2} \mathrm{~S}$-absorbed IL is very high resulting in 
long absorption equilibrium time (Huang et al., 2016b; Xue et al., 2018). The chemical industry for gas separation still prefers gas-liquid systems with low viscosity or gas-solid systems due to the ease of operation and the economic criteria; it is desirable to minimize the amount of utilized ILs in an industrial process. Wang et al. (2019) found that (bmim) $\mathrm{TF}_{2} \mathrm{~N}$ is a potential ionic liquid that can remove both $\mathrm{H}_{2} \mathrm{~S}$ and $\mathrm{CO}_{2}$, with a $\mathrm{CO}_{2}$ removal rate of $97.6 \%$ and $\mathrm{H}_{2} \mathrm{~S}$ removal rate of $95.3 \%$, and can save a lot of refrigeration energy. However, it can not meet the requirements of gas refining, and its application is still limited. Ge et al. (2019) developed a new polyfiber ionic liquid with good adsorption capacity of $\mathrm{H}_{2} \mathrm{~S}$ at room temperature, up to $1.75 \mathrm{mmol} \mathrm{L}^{-1}$, but its breakthrough sulfur capacity was low, $0.92 \mathrm{mmol} \mathrm{L}^{-1}$, and it could not be used for sulfur recovery.

To take advantage of IL properties while avoiding their negative aspects, on the one hand, supported ionic liquid or ionic liquid combined system could overcome the shortcomings of ionic liquids (Wang et al., 2016; Xue et al., 2018), such as, high cost, high viscosity, and cut the amount of utilized ILs, but the complex synthesis of ionic liquid must proceed, and most solvents in the combined system are toxic; on the other hand, a new type of solvents, deep eutectic solvents (DESs), are emerging as versatile alternatives to ILs that provide similar features. DESs have benign characteristics such as comparatively low cost, low toxicity, high biodegradability and accessible synthesis (Smith et al., 2014; Azizi and Edrisi, 2017). DESs could be obtained by simply mixing the hydrogen bond donor (HBD; such as metal chloride) and hydrogen bond acceptor (HBA; such as quaternary ammonium halide salt) by heating and stirring, without additional purification operations, leading to a significant depression of the freezing point (Gorke et al., 2008; Dai et al., 2013; Smith et al., 2014; Azizi and Edrisi, 2017). Although DESs which is regarded as another class of IL variants have been successfully applied in different research fields, few of them have been reported for $\mathrm{H}_{2} \mathrm{~S}$ removal, and some functional DESs of high viscosity are inadaptable for gas separation as a liquid-phase absorbent (Smith et al., 2014). They have been rarely reported for $\mathrm{H}_{2} \mathrm{~S}$ removal. Liu et al. (2019a) has studied four kinds of metal-based low transition temperature mixtures, which were synthesized by metal chlorides and choline chlorides, and the results were satisfactory. Furthermore, supported DESs (SDESs) have a promising application in $\mathrm{H}_{2} \mathrm{~S}$ removal, on the one hand to minimize the unfavorable sides for ionic liquid gas-liquid system and the use of DESs, and on the other side to improve the utilization rate of DESs (Huang et al., 2019).

Considering these facts and inspired by the early work of our groups in DESs systems (Ma et al., 2019a), we became interested in the immobilization of DESs onto silica materials. Herein, fumed silica (FS) was selected as the supported materials because of the specific performance characteristics, high chemical stability and low cost (Liu and Maciel, 1996; Liu et al., 2019b), Si-OH from FS could enhance the cation and anion interaction to stabilize DESs in the space more firmly (Qian et al., 2018). The main aim of this work is to optimize the ratio of HBA and HBD of the DES, and test the $\mathrm{H}_{2} \mathrm{~S}$ removal efficiency of DESs immobilized on fumed silica prepared by simply physical immobilization. The $\mathrm{H}_{2} \mathrm{~S}$ removal mechanism and regeneration performance were evaluated.

\section{MATERIALS AND METHODS}

\section{Materials}

$\mathrm{H}_{2} \mathrm{~S}(99.999 \%)$ and $\mathrm{N}_{2}(99.999 \%)$ were supplied by Jinan Deyang Special Gas Co., Ltd. (Shandong, China). Triethylamine hydrochloride (TAECl; $99 \mathrm{wt} \%$ ), cupric chloride $\left(\mathrm{CuCl}_{2} ; 99 \mathrm{wt} \%\right)$ and iron trichloride $\left(\mathrm{FeCl}_{3}\right.$; $99 \mathrm{wt} \%$ ) was purchased from Shanghai Macklin Biochemical Co., Ltd. Fumed silica was purchased from Sunny Chemicals (H.K.) Ltd. Carbon disulfide $\left(\mathrm{CS}_{2}\right.$; metal basis, $99.99 \mathrm{wt} \%$ ) was purchased from Sinopharm Chemical Reagent Co., Ltd. The TH-990S portable smoke analyzer was purchased from Wuhan Tianhong Instrument Group and the D08-1F flow indicators were provided from Beijing Sevenstar Electronics Co., Ltd. All the chemicals were used directly without further purification.

\section{Preparation of DESs and SDESs}

TAECl and $\mathrm{CuCl}_{2}$ were used as HBA and HBD of the DES, respectively. $13.76 \mathrm{~g}$ of TAECl was mixed with 13.44 $\mathrm{g}$ of $\mathrm{CuCl}_{2}$ (molar ratio is $1: 1$ ) and the mixture were heated to $70^{\circ} \mathrm{C}$ under stirring in inert atmosphere for $24 \mathrm{~h}$, and finally DES TAECuCl 3 was obtained. The other DESs with different molar ratio of TAECl and $\mathrm{CuCl}_{2}$ were synthesized using the same method. The DES product is a thick blackbrown liquid at $70^{\circ} \mathrm{C}$, but semisolid at room temperature.

The SDESs was achieved via inverse supported approach (Kazuya et al., 2005) without complicated synthetic modification. Firstly, the high-viscosity DES of certain amount was dissolved in $70 \mathrm{~mL}$ mixed solvents (the volume ratio of acetonitrile to ethanol is $3: 1$ ). Then, FS was added to the above mixture, and treated with ultrasound at $120 \mathrm{~W}$ for $10 \mathrm{~min}$. The solvents were then evaporated at reduced pressure, and the resulting mixture was finally dried for 24 $\mathrm{h}$ at $60^{\circ} \mathrm{C}$ in vacuum. The illustration of molar ratios and loading amount was listed in Table 1.

Table 1. The notes and molar ratios of samples.

\begin{tabular}{|c|c|c|c|c|c|c|}
\hline Ratios $^{\mathrm{a}}$ & $0.6: 1$ & $1: 1$ & $1.2: 1$ & $1.4: 1$ & $1.6: 1$ & $1.8: 1$ \\
\hline $\begin{array}{l}\text { DESs } \\
\text { Notes }\end{array}$ & $\begin{array}{l}\mathrm{TAE}_{0.6} \mathrm{CuCl}_{2.6} \mathrm{TAE}_{0.8} \mathrm{CuCl}_{0.8} \\
\mathrm{TAE}_{\mathrm{x}} \mathrm{CuCl}_{\mathrm{y}} @ \mathrm{FS} / \mathrm{z} \mathrm{wt}_{0}^{\mathrm{b}}\end{array}$ & $\mathrm{TAECuCl}_{3}$ & $\mathrm{TAE}_{1.2} \mathrm{CuCl}_{3.2}$ & $\mathrm{TAE}_{1.4} \mathrm{CuCl}_{3.4}$ & $\mathrm{TAE}_{1.6} \mathrm{CuCl}_{3.6}$ & $\mathrm{TAE}_{1.8} \mathrm{CuCl}_{3.8}$ \\
\hline
\end{tabular}




\section{Desulfurization Test}

The desulfurization test was carried out using two quartz tubes (inner diameter of $6 \mathrm{~mm}$ and height of $10 \mathrm{~cm}$ ) connected in series with silicone hose. $0.5 \mathrm{~g}$ of sorbent (the length of sorbents layer were $60 \mathrm{~mm}$ ) was packed into each tube and the desulfurization temperature was controlled by thermostat water bath. A gas mixture (nitrogen as the carrier gas) containing $800 \mathrm{ppm}$ (1231 $\mathrm{mg} \mathrm{L}^{-1}$ at standard condition) of $\mathrm{H}_{2} \mathrm{~S}$ was passed through the sorbent at a flow rate of $100 \mathrm{~mL} \mathrm{~min}^{-1}$. The $\mathrm{H}_{2} \mathrm{~S}$ concentration of the outlet gas was detected by a TH-990S hydrogen sulfide gas analyzer. The residual $\mathrm{H}_{2} \mathrm{~S}$ gas was absorbed by $\mathrm{NaOH}$ solution before discharging into the atmosphere. The $\mathrm{H}_{2} \mathrm{~S}$ removal efficiency of the desulfurizer was calculated by Eq. (1). $C_{\text {in }}$ and $C_{\text {out }}$ are the inlet and outlet concentration of $\mathrm{H}_{2} \mathrm{~S}\left(\mathrm{mg} \mathrm{m}^{-3}\right)$, respectively (Liu et al., 2019a).

$H_{2} S$ removal efficiency $(\%)=\frac{C_{\text {in }}-C_{\text {out }}}{C_{\text {in }}} \times 100 \%$

The breakthrough curve was expressed as a plot of the outlet concentration of $\mathrm{H}_{2} \mathrm{~S}$ versus time. In addition, the breakthrough sulfur capacity $\left(S_{c a p}\right)$ was calculated using Eq. (2) when the outlet concentration of $\mathrm{H}_{2} \mathrm{~S}$ was higher than $20 \mathrm{mg} \mathrm{m}^{-3}$ (Shen et al., 2018).

$S_{\text {cap }}=\frac{M_{S}}{M_{\mathrm{H}_{2} S}} \times \frac{Q_{\mathrm{H}_{2} S}}{m}\left[\int_{0}^{t}\left(C_{i n}-C_{\text {oit }}\right) d t\right] \times 10^{-6}$

where $S_{\text {cap }}$ represents the breakthrough sulfur capacity of sorbents; $M_{S}$ and $M_{H_{2} S}$ are the molar weight $\left(\mathrm{g} \mathrm{mol}^{-1}\right)$ of S and $\mathrm{H}_{2} \mathrm{~S}$, respectively; $m$ is the weight of sorbents; $Q_{H_{2} S}$ is the $\mathrm{H}_{2} \mathrm{~S}$ gas flow rate; $t$ is the reaction time (min) for desulfurization.

In order to measure the efficiency of the unit adsorbent $(\omega)$, we calculated the molar ratio of metal ions to absorbed $\mathrm{H}_{2} \mathrm{~S}$. The formula was shown in Eq. (3) (Nath and Yadav, 2018):

$$
\omega=\frac{n_{H_{2} S}}{n_{C u}}
$$

\section{Characterization}

The Fourier transform infrared spectroscopy of materials were studied using FT-IR spectrophotometer (IRAffinity1S; Shimadzu, Japan). The surface morphologies of materials were obtained by scanning electron microscopy (SEM; Regulus8220; Hitachi, Japan). The element composition and valence state of materials were obtained by X-ray photoelectron spectroscopy with multifunctional imaging electron spectrometer (Thermo Scientific ESCALAB 250 XI; Thermo Fisher, USA). The specific surface area of materials was determined by the BET (Brunauer-Emmett-Teller) and the pore size distribution was calculated by the BJH (BarrettJoymer-Halenda) from the isotherm of adsorption branch with automatic specific surface area and porosity analyzer
(TriStar II 3020; Micromeritics, USA).

\section{RESULTS AND DISCUSSION}

\section{Characterization of DESs and SDESs \\ Fourier Transform Infrared Spectrometer}

The inverse supported method is simple and easy without complicated synthetic modification on FS. It is just a process of physical deposition, therefore, the characteristics of the sorbent depend solely on the DESs and FS (Jaiboon et al., 2014). The FT-IR spectrum of SDESs were shown in Fig. 1. Due to the small amount of solid load, the adsorbents maintains the infrared characteristics of FS itself. The peak at $798 \mathrm{~cm}^{-1}$ is the symmetric stretching vibration peak of $\mathrm{Si}-\mathrm{O}$, and the peak at $958 \mathrm{~cm}^{-1}$ was attributed to the structure of Si-OH. The peak at $1095 \mathrm{~cm}^{-1}$ was attributed to $\mathrm{Si}-\mathrm{O}-\mathrm{Si}$ anti-scale vibration peak. At last, the broad peak at $3429 \mathrm{~cm}^{-1}$ was belong to the $-\mathrm{OH}$ of $\mathrm{H}_{2} \mathrm{O}$, which may come from the air during the process of sample preparation (Cheng et al., 2019).

\section{Surface Area and Porosity Analysis}

The $\mathrm{N}_{2}$ adsorption-desorption isotherms of FS and TAECuCl ${ }_{3} @ \mathrm{FS} / 10$ wt\% were shown in Figs. 2(a) and 2(b). The typical Type IV isotherms with $\mathrm{H} 4$ characteristics loop were obtained. There are some mesoporous, slit pores and inter-particle pores (mainly macropores) in both samples. The DES was well dispersed in the mesopores of the silica material and the FS kept its original structure after the loading of DES (Jaiboon et al., 2014). The surface area and pore volumes of SDESs can be seen in Table 2. The surface area of FS $\left(153.3172 \mathrm{~m}^{2} \mathrm{~g}^{-1}\right)$ decreased after the deposition of DESs. The same situation was found for the pore volumes of the SDESs. The pore size distribution curve of FS before and after DESs loading was shown in Fig. 3. It can be found that the mesopores and macropores were dominant before and after the deposition of DESs, and there were a few microspores.

With the increase of the loading amount, the specific surface area of FS decreased, while the pore width increased. This showed that with the increase of the loading amount, a large number of DESs deposited on the surface of FS, leading to the reducing of the specific surface area for FS. The pore volume increased first and then decreased, because with the increase of loading amount, the micropores and mesopores are filled out by DESs first, and then the excessive loading could lead to the deformation of the surface structure or collapse (Widiana et al., 2019). Although the loading substance DES can improve the removal ability of $\mathrm{H}_{2} \mathrm{~S}$ by FS, it should be emphasized that the high specific surface and pore volume also plays the important roles in the adsorption of $\mathrm{H}_{2} \mathrm{~S}$. In particular, mesoporous plays a more important role in catalytic oxidation (Soriano et al., 2009; Sun et al., 2013; Kwok et al., 2017; Wang et al., 2018; Li et al., 2019).

\section{Surface Morphology Analysis}

The SEM image of the samples was shown in Figs. 4(a)4(e). There were many pores on the surface of the original fumed silica in Fig. 4(a). With the increase of loading amount 


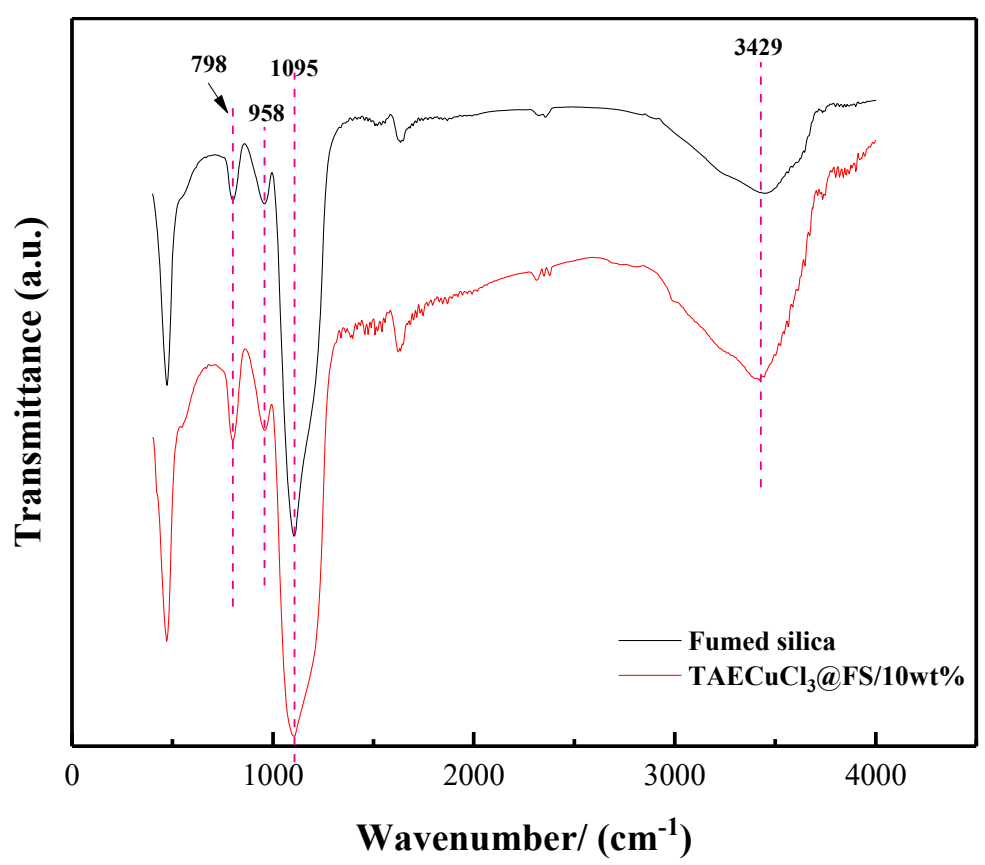

Fig. 1. FT-IR spectra of FS and SDESs (TAECuCl $\left.\mathrm{T}_{2} \mathrm{FS} / 10 \mathrm{wt} \%\right)$.
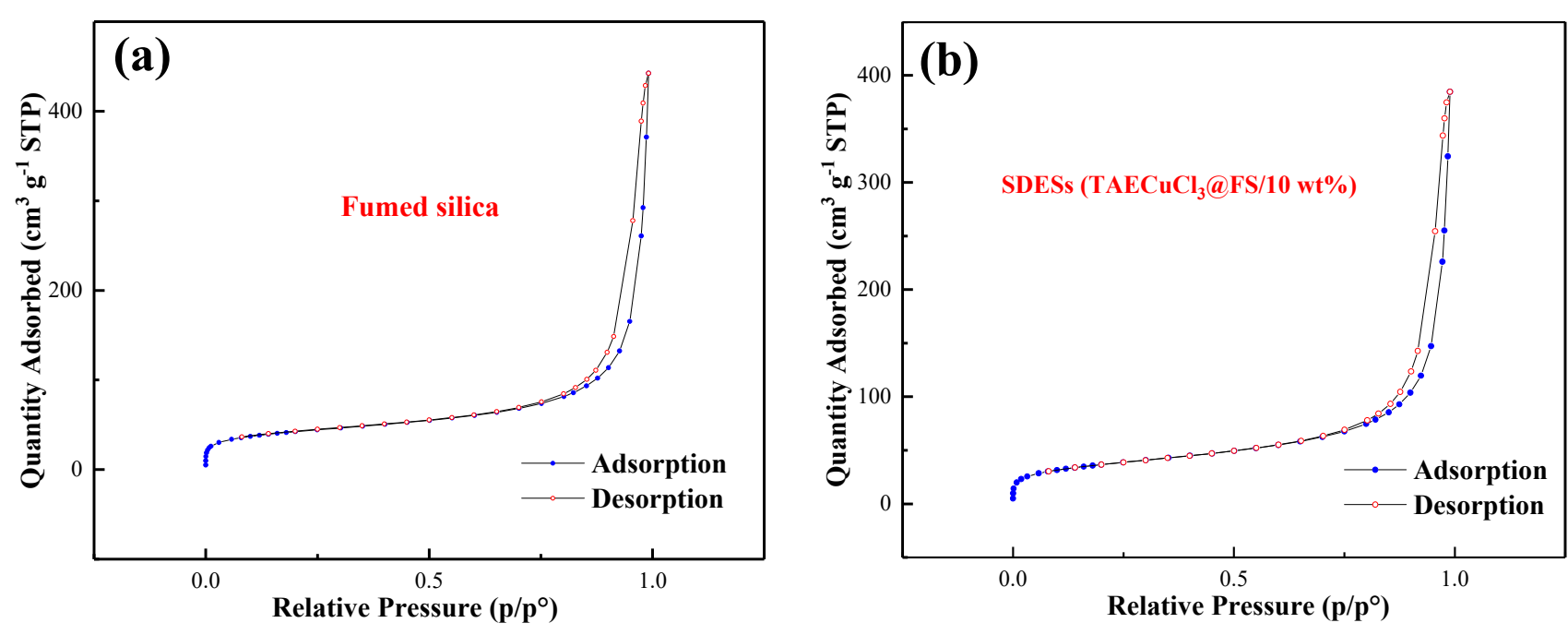

Fig. 2. Curves of nitrogen adsorption-desorption of (a) FS and (b) TAECuCl $\mathrm{T}_{3} @ \mathrm{FS} / 10 \mathrm{wt} \%$.

Table 2. Physical parameters of three kinds of sorbents.

\begin{tabular}{|c|c|c|c|}
\hline Desulfurizer & Surface are $\left(\mathrm{m}^{2} \mathrm{~g}^{-1}\right)$ & Pore width (nm) & Pore volumes $\left(\mathrm{cm}^{3} \mathrm{~g}^{-1}\right)$ \\
\hline FS & 153.3172 & 17.8534 & 0.6843 \\
\hline $\mathrm{TAECuCl}_{3} @ \mathrm{FS} / 10 \mathrm{wt} \%$ & 132.5190 & 17.9551 & 0.5948 \\
\hline $\mathrm{TAECuCl}_{3} @ \mathrm{FS} / 20 \mathrm{wt} \%$ & 124.0691 & 20.2953 & 0.6295 \\
\hline
\end{tabular}

for DESs, the granular volume of FS surface gradually increased and the surface gradually became smooth. When its surface was deposited with $10 \mathrm{wt} \%$ DES in Fig. 4(b), it can be seen that the surface of FS becomes smoother and denser, indicating that DESs has a nice and stable load on the surface FS. It could be found that there was still a developed mesoporous structure on the surface of FS, which ensured the catalysis and adsorption properties of the material itself. The successful incorporation of DESs into the fumed silica framework can be identified and estimated by EDS elemental mapping of $\mathrm{Cu}$, and the result was shown in Figs. 4(d) and 4(e). The blue dots in the figure represent the $\mathrm{Cu}$ elements distributed on the surface of FS. $\mathrm{Cu}$ in the structure of nano-composite can be further confirmed. 


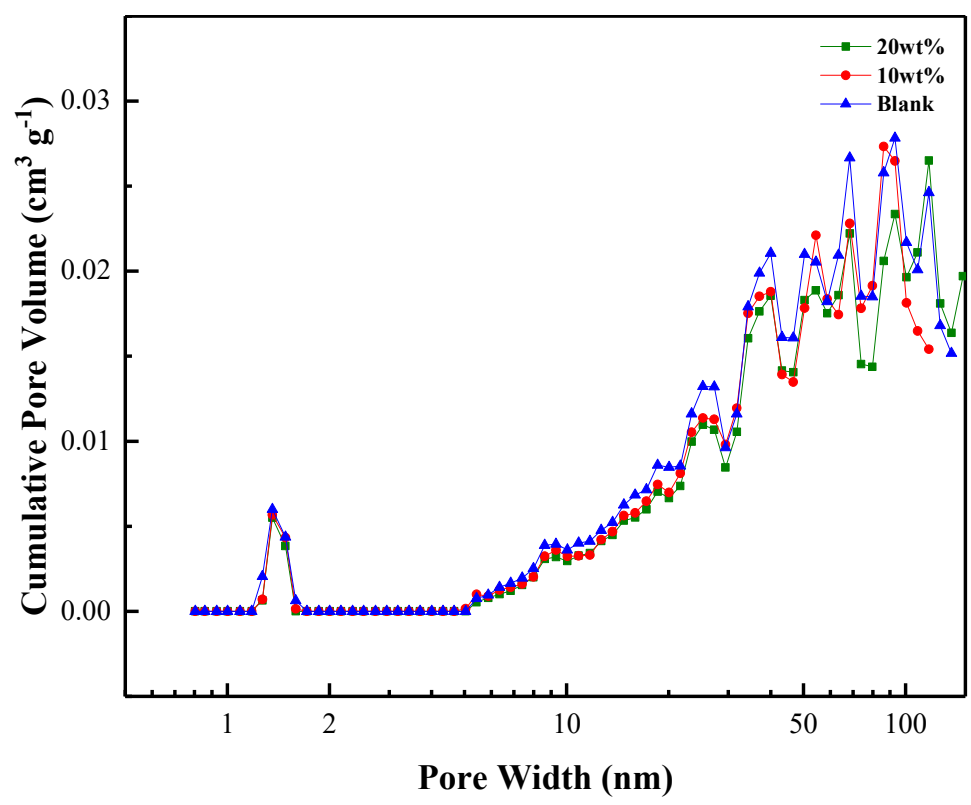

Fig. 3. The pore diameter distribution curves of the materials.

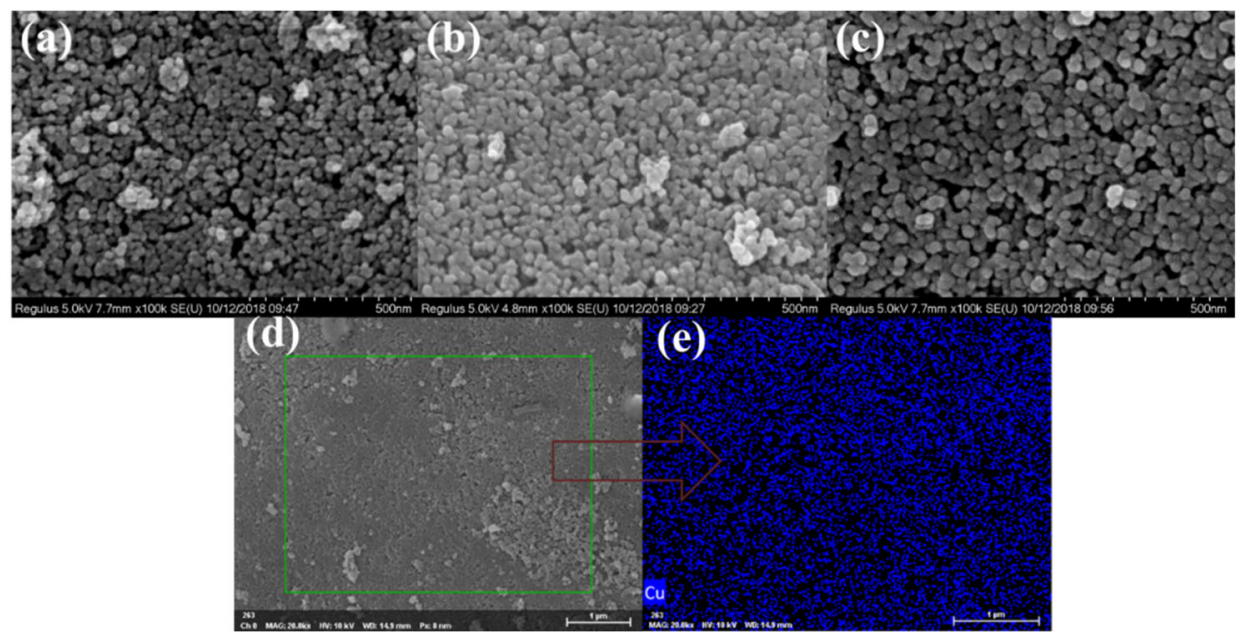

Fig. 4. The SEM images of FS and SDESs. (a) Fumed silica without DESs, (b) TAECuCl 3 @FS/10wt $\%,(c)$ TAECuCl 3 FS/20 $\mathrm{wt} \%$, and $(\mathrm{d}, \mathrm{e})$ EDS elemental mapping of $\mathrm{Cu}$ before adsorption.

Similar to room-temperature ionic liquid, in pure DESs, complex grid-like hydrogen bonds will formed between molecules (Dong et al., 2006). This structure will solidify the DESs molecules, increase the viscosity of materials, prevent the $\mathrm{H}_{2} \mathrm{~S}$ molecules from entering the grid, and greatly affect the mass transfer efficiency (Lungwitz and Spange, 2008; Dong and Zhang, 2012), which results in low utilization of DESs and poor catalytic oxidation. The DESs molecules are connected by planar grid hydrogen bonds, and it is no longer a $3 \mathrm{D}$ grid structure, which can greatly improve the utilization rate of DESs (Shi et al., 2005). When the proportion and content of immobilized DESs is appropriate, it will form a nanometer thin layer of DESs on the surface of fumed silica. Moreover, some physical and chemical properties of the DESs will change under the nanometer conditions to enhance the catalytic ability.

\section{Determination of Optimum Conditions}

Effect of Different Loading Substances on FS

In this part, we did a series of single factor experiments to determine the optimum condition (loading substances, loading amount, and desulfurization temperature) in the desulfurization system. The $\mathrm{H}_{2} \mathrm{~S}$ removal efficiency (\%) and sulfur capacity $\left(\mathrm{mg} \mathrm{g}^{-1}\right)$ were selected as evaluation index.

The sulfur capacities of SDESs under different molar ratios of TAECl and $\mathrm{CuCl}_{2}$ in DESs from 0.6:1 to 1.8:1 was tested, and the condition of desulfurization was the temperature of $30^{\circ} \mathrm{C}$, loading rate of $10 \mathrm{wt} \%$, and the gas flow rate of $100 \mathrm{~mL} \mathrm{~min}^{-1}$. The breakthrough sulfur capacity of the SDESs were measured and showed in Figs. 5(a) and 5(b).

As it can be observed that the sulfur capacity of $\mathrm{H}_{2} \mathrm{~S}$ in $\mathrm{TAECuCl}_{3} @ \mathrm{FS} / 10 \mathrm{wt} \%$ (when the molar ratio is $1: 1$ ) is higher than that of other different molar ratios of TAECl and $\mathrm{CuCl}_{2}$. The dynamic viscosity model of DESs under different 
molar ratios was shown in Fig. 6, and the dynamic viscosity of $\mathrm{TAECuCl}_{3}$ DESs increased sharply with the decrease or increase of molar ratio of TAECl and $\mathrm{CuCl}_{2}$. Not only did it reduce the number of active sites, but also the high viscosity of the DESs limits the mass transfer of $\mathrm{H}_{2} \mathrm{~S}$, which results in the sulfur capacity of $\mathrm{H}_{2} \mathrm{~S}$ decrease. DESs of high viscosity are easy to be agglomerated on the surface of fumed silica. In addition, $\mathrm{Cu}^{2+}$ is used as oxidant and complexing agent, and TAECl is used as the activator of hydrogen sulfide molecule. The increase or decrease of its mixture ratio will make the activated $\mathrm{HS}^{-}$surplus and premature overflow, which is not conducive to fine desulfurization (Chatterjee et al., 2018).

Original FS, TAECl@FS/5 wt $\%$ and $\mathrm{CuCl}_{2} @ \mathrm{FS} / 5$ wt $\%$ were first studied. Since there is little difference between TAECl and $\mathrm{CuCl}_{2}$ on the relative molecular mass, TAECuCl 3 @FS $/ 10$ wt $\%$ can be regarded as TAECl@FS $/ 5$ wt $\%$ and $\mathrm{CuCl}_{2} @ \mathrm{FS} / 5 \mathrm{wt} \%$. It can be seen from the data that the breakthrough time of original FS was 174 seconds (not shown in the figure), and its desulfurization capacity is weak due to its pore structure and physical adsorption. The desulfurization ability of TAECl@FS/5 wt $\%$ is slightly weaker than that of original FS, its breakthrough time was

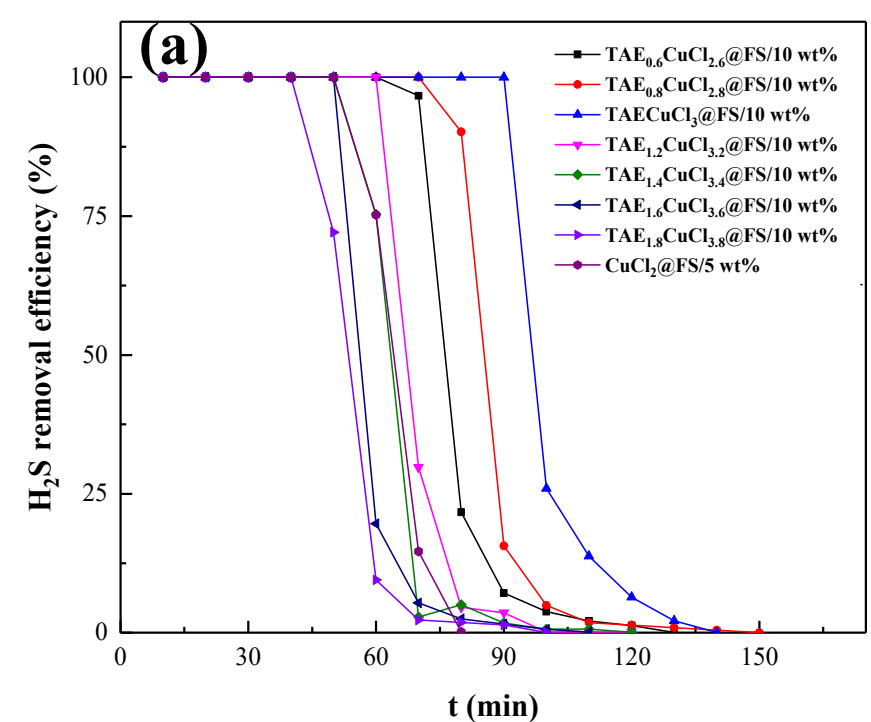

132 seconds (not shown in the figure). Because the pore structure is the important factor rather than amino adsorption by TAECl, and the deposition of TAECl on FS blocks the pores and does not benefit to adsorption of $\mathrm{H}_{2} \mathrm{~S}$. Although $\mathrm{CuCl}_{2} @ \mathrm{FS} / 5 \mathrm{wt} \%$ has higher desulfurization capacity and longer breakthrough time, it is still weaker than TAECuCl ${ }_{3} @ \mathrm{FS} / 10 \mathrm{wt} \%$ and cannot be regenerated.

\section{Effect of Different Loading Amount of TAECuCl $\mathrm{TH}_{3}$ on FS}

To confirm the best loading amount, SDES with different loading amount of $\mathrm{TAECuCl}_{3}$ was tested for $\mathrm{H}_{2} \mathrm{~S}$ removal, and the results are shown in Figs. 7(a) and 7(b). $\mathrm{H}_{2} \mathrm{~S}$ removal efficiency of SDESs increased as the loading amount of $\mathrm{TAECuCl}_{3}$ increasing from $0 \%$ to $20 \%$. Although high loading could lead to high sulfur capture, it was unfavorable for the dispersion of active phase in carrier material, resulting in a decline in utilization rate of active phase during desulfurization process. As the loading increasing, more microspores in the carrier material were clogged by DESs, and the mass transfer resistance of $\mathrm{H}_{2} \mathrm{~S}$ into the pore increased, which made it difficult to fully react with the chemically active sites in SDESs. Moreover, excessive DESs can form large aggregates that

Fig. 5. (a) $\mathrm{H}_{2} \mathrm{~S}$ breakthrough sulfur curves and (b) capacity of SDESs for different molar ratios of $\mathrm{TAECl}_{\mathrm{and}} \mathrm{CuCl}_{2}$.

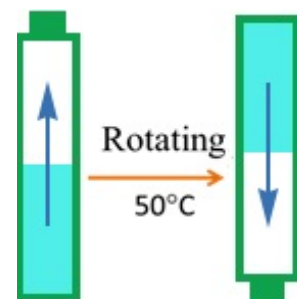
High $0.6: 1$

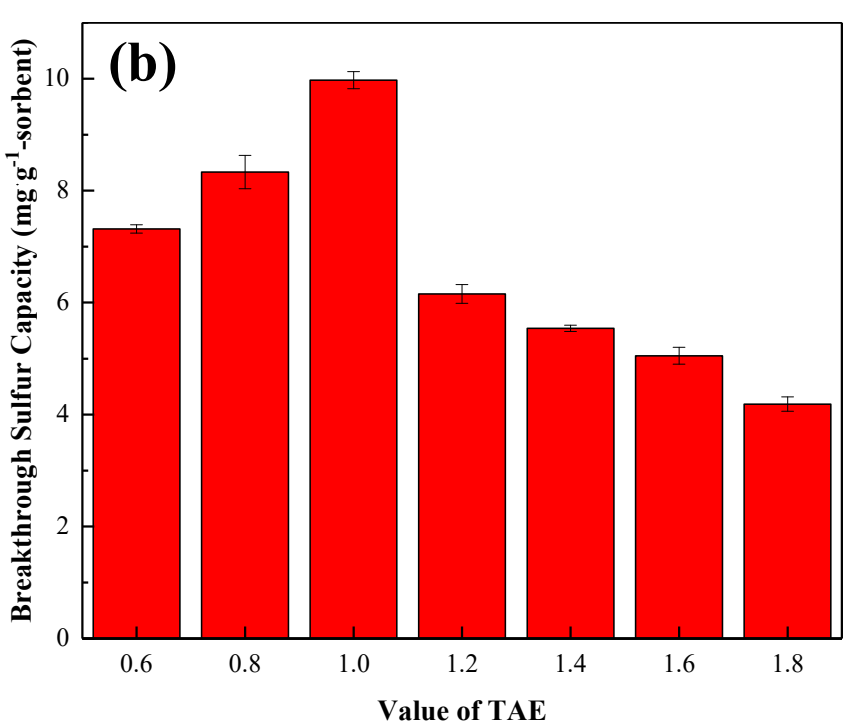

\section{(a)}



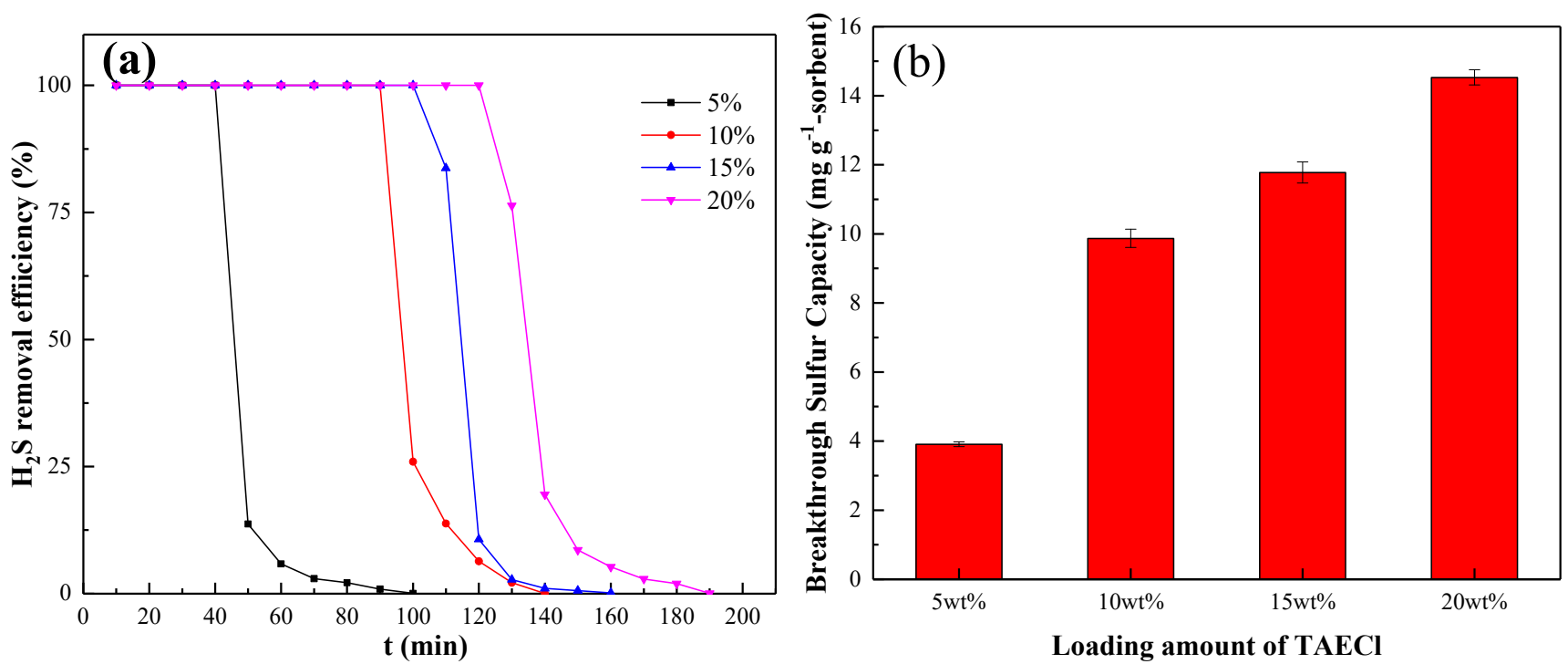

Fig. 7. (a) $\mathrm{H}_{2} \mathrm{~S}$ breakthrough curves and (b) sulfur capacity of $\mathrm{TAECuCl}_{3} @ \mathrm{FS}$ with different loading amount of $\mathrm{TAECuCl}_{3}$.

cover the surface of FS and prevent the carrier material from exerting its effect (Ma et al., 2019b). After a comprehensive consideration, the optimal content of SDESs was $10 \mathrm{wt} \%$.

Here, we also studied the adsorption efficiency $(\omega)$ in Eq. (3) described above, and the value of $\omega$ reflecting the utilization rate of metal active sites is summarized in Table 3 . The highest value of $\omega$ is 0.8669 , it is a high level, which can be explained as follows: First, FS can interact with DES to fully reduce the size of surface DESs micro clusters and promote the transformation of metal active sites; secondly, the addition of copper can also significantly reduce the limit of solid diffusion (Balsamo et al., 2016); thirdly, copper containing $\mathrm{ZnS}$ has a higher sulfur anion mobility, leading to a more complete reaction (Balsamo et al., 2016), and copper ions in SDESs may play a similar role in this study; fourthly, in this study, dense metal sulfide layer will not be formed, so the reaction is more sufficient (Balsamo et al., 2016).

\section{Effect of Different Desulfurization Temperature}

Desulfurization performance of the sorbents depended critically on temperature, which controlled $\mathrm{S}^{2-} / \mathrm{Cu}^{2+}$ react rate, gas diffusion efficiency, the viscosity of DESs, etc. The $\mathrm{H}_{2} \mathrm{~S}$ removal performance of SDESs in different temperature was shown in Figs. 8(a) and 8(b). It can be seen that when the temperature is over $30^{\circ} \mathrm{C}$ the removal efficiency of $\mathrm{H}_{2} \mathrm{~S}$ by SDESs decreases with the increase of temperature. The breakthrough and saturation sulfur adsorption capacities of SDESs reached the maximum value at $30^{\circ} \mathrm{C}$. According to previous research, this kind of absorption is an exothermal reaction (Min et al., 2015). When the temperature is $20^{\circ} \mathrm{C}$, the sulfur capacity is lower than $30^{\circ} \mathrm{C}$, it may due to the lower temperature increases the viscosity of DESs and affects the mass transfer effect. The higher temperature can enhance the molecular mobility and interaction probability of the reactants, and hence promote the adsorption of $\mathrm{H}_{2} \mathrm{~S}$ molecular on SDESs. However, higher temperature can hinder the $\mathrm{H}_{2} \mathrm{~S}$ absorption due to exothermic reaction. According to experiment result, the low temperature $\left(30^{\circ} \mathrm{C}\right)$ becomes the best choice for $\mathrm{H}_{2} \mathrm{~S}$ removal. The SESs has a highest breakthrough sulfur capacity in optimum condition of $9.97 \mathrm{mg} \mathrm{g}^{-1}$ of sorbent (in Table 3).

\section{Recycle of SDESs for $\mathrm{H}_{2} \mathrm{~S}$ Absorption}

To evaluate the recyclability of SDESs for $\mathrm{H}_{2} \mathrm{~S}$ absorption, the regeneration of SDESs was carried by sweeping air directly. The temperature for regeneration is $20^{\circ} \mathrm{C}$, and using the air flow rate of $50 \mathrm{~mL} \mathrm{~min}^{-1}$. The SDESs is then extracted by $\mathrm{CS}_{2}$ and dried. The decrease of its desulfurization capacity may be due to the gradual collapse of the structure and the failure to completely remove $\mathrm{S}$. The regeneration performance of SDESs is shown in Fig. 9. The $\mathrm{H}_{2} \mathrm{~S}$ removal efficiency was test after $2 \mathrm{~h}$ of absorption, and was all above

Table 3. A desulfurization performance summary over $\mathrm{TAECuCl}_{3}$-activated sorbents.

\begin{tabular}{|c|c|c|c|c|}
\hline Absorption & $S_{\text {cap }}$ & $\omega$ & Loading $\% \mathrm{wt}$ & Ref. \\
\hline $\mathrm{TAECuCl}_{3} @ \mathrm{FS} / 5 \mathrm{wt} \%$ & 3.87 & 0.6440 & 5 & This work \\
\hline $\mathrm{TAECuCl}_{3} @ \mathrm{FS} / 10 \mathrm{wt} \%$ & 9.97 & 0.8669 & 10 & \\
\hline $\mathrm{TAECuCl}_{3} @ \mathrm{FS} / 15$ wt $\%$ & 12.06 & 0.7296 & 15 & \\
\hline $\mathrm{TAECuCl}_{3} @ \mathrm{FS} / 20$ wt $\%$ & 14.34 & 0.6771 & 20 & \\
\hline $\mathrm{TAECuCl}_{3}$ & 28.98 & 0.2436 & 100 & \\
\hline $\mathrm{TAECu}_{0.6} \mathrm{Cl}_{2.6} @ \mathrm{FS} / 10 \mathrm{wt} \%$ & 7.39 & 0.5163 & 10 & \\
\hline $\mathrm{TAECu}_{1.8} \mathrm{Cl}_{3.8} @ \mathrm{FS} / 10 \mathrm{wt} \%$ & 4.16 & 0.4903 & 10 & \\
\hline $\mathrm{TAECuCl}_{3}-\beta-\mathrm{CDGZ}$ & 7.75 & 0.60 & 14 & Our previous work (Ma et al., 2019a) \\
\hline
\end{tabular}



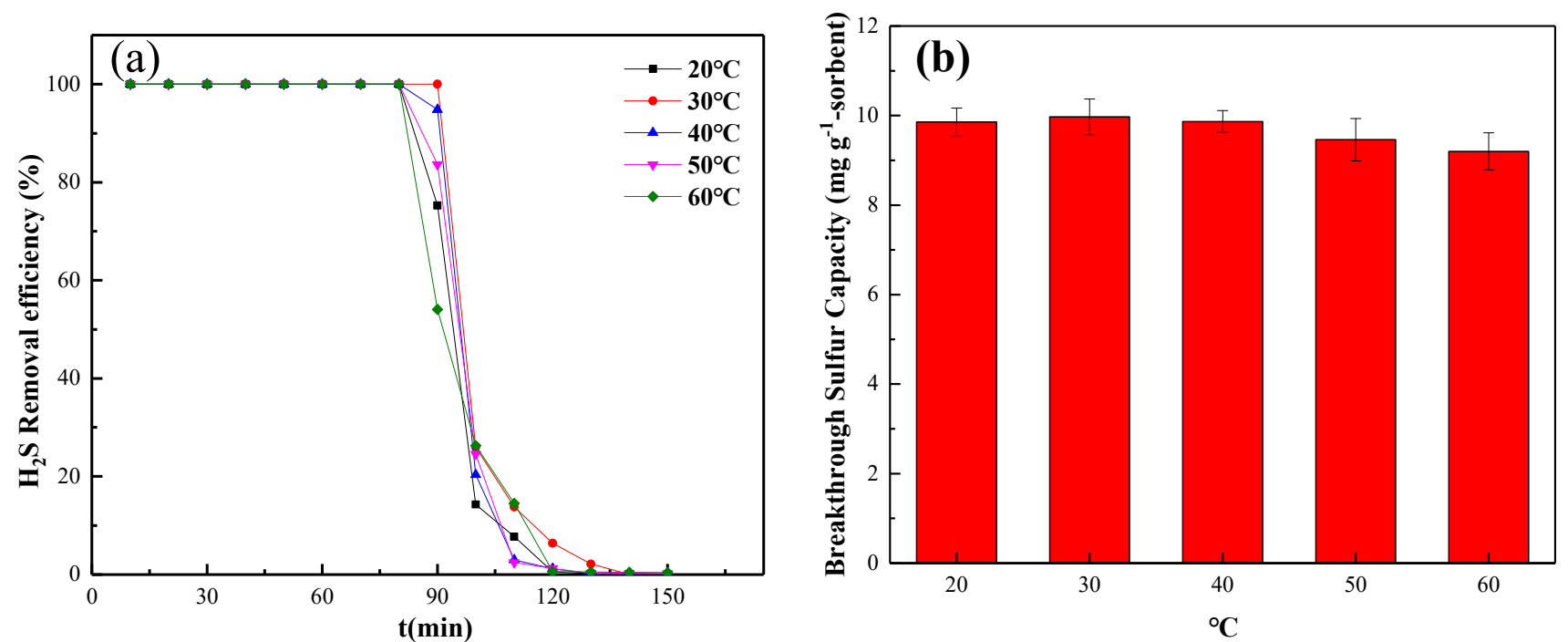

Fig. 8. (a) $\mathrm{H}_{2} \mathrm{~S}$ breakthrough curves and (b) sulfur capacity of $\mathrm{TAECuCl}_{3} @ \mathrm{FS} / 10 \mathrm{wt} \%$ at different temperature.

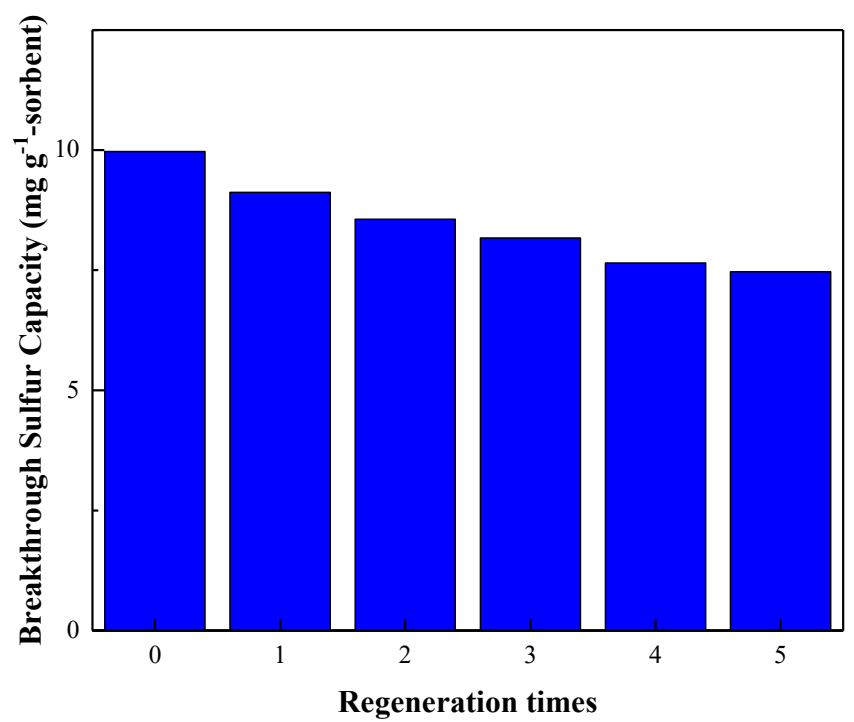

Fig. 9. Regeneration performance of $\mathrm{TAECuCl}_{3} @ \mathrm{FS} / 10 \mathrm{wt} \%$.

$73 \%$ within 4 cycles, which demonstrate that the SDESs have an excellent regeneration performance in the process of $\mathrm{H}_{2} \mathrm{~S}$ removal. The color change of SDESs in the process of synthesis, adsorption and regeneration was shown in Fig. 10.

Because the recovered elemental sulfur and SDESs are both solid, it is impossible to recover elemental sulfur through simple filtration. The two possible recovery methods are as follows: Firstly, the adsorbent was extracted by $\mathrm{CS}_{2}$, and then the elemental sulfur was obtained after removing the solvent $\mathrm{CS}_{2}$; secondly, the $\mathrm{H}_{2} \mathrm{~S}$-adsorbed SDES was purged with hot $\mathrm{N}_{2}$ to separate out sublimate elemental sulfur and condense it under appropriate conditions.

\section{Analysis of Desulfurization Products}

A small amount of yellow, hard and brittle solid were obtained by vacuum evaporation of $\mathrm{CS}_{2}$ solution containing desulfurization products at $40^{\circ} \mathrm{C}$ and under vacuum for $24 \mathrm{~h}$. The obtained crystal was analyzed by XRD, and the results are shown in Fig. 11. The position of the main diffraction peaks of the product is consistent with the rhombic sulfur (No. 8-247) in the JCPDS standard spectrum. Therefore, it can be determined that the desulfurization product contains a small amount of rhombic sulfur crystal. Since $\mathrm{Cu}^{2+}$ is more oxidizing than $\mathrm{Fe}^{2+}$ but weaker than $\mathrm{Fe}^{3+}$, the oxidation product contains a certain amount of $\mathrm{S}$.

To investigate the reaction mechanism, chemical valence states of element $\mathrm{Cu}$ and $\mathrm{S}$ in TAECuCl${ }_{3} @ \mathrm{FS} / 10 \mathrm{wt} \%$ in the whole process were analyzed by XPS, and were shown in Figs. 12(a)-12(d). The XPS spectrum of $S$ after adsorption was shown in Fig. 12(a). The valence state of $\mathrm{S}$ was confirmed by binding energy within the range of $162-172 \mathrm{eV}$. It showed that $\mathrm{S}(0) 2 \mathrm{p}_{3 / 2}$ appeared at $164.20 \mathrm{eV}$, and $\mathrm{S}(\mathrm{II}) 2 \mathrm{p}_{2 / 3}$ appeared at $167.65 \mathrm{eV}$, and the binding energy position of the $\mathrm{S} 2 \mathrm{p}_{2 / 3}$ from $\mathrm{SO}_{4}{ }^{2-}$ of sample is $169.10 \mathrm{eV}$, indicating that the valence state of S element is +6, -2 and 0 (Wagner and Taylor, 1980; de Jong et al., 1993; Yu et al., 1990). During the regeneration 


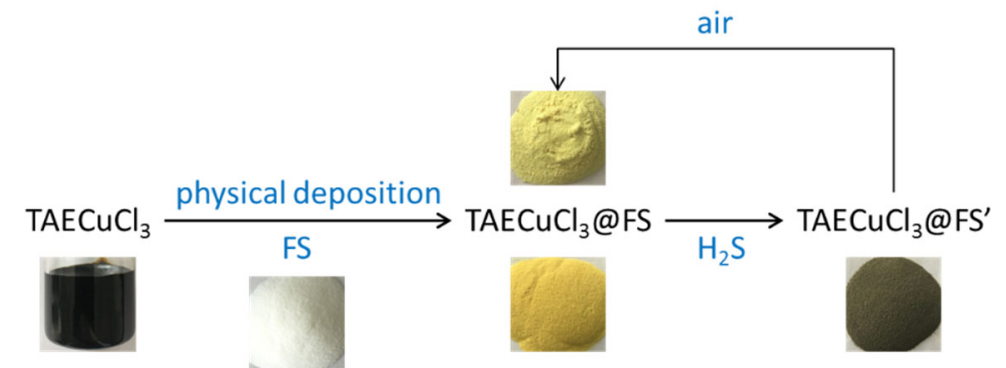

Fig. 10. The color changes of SDESs in the process of synthesis, adsorption, and regeneration.

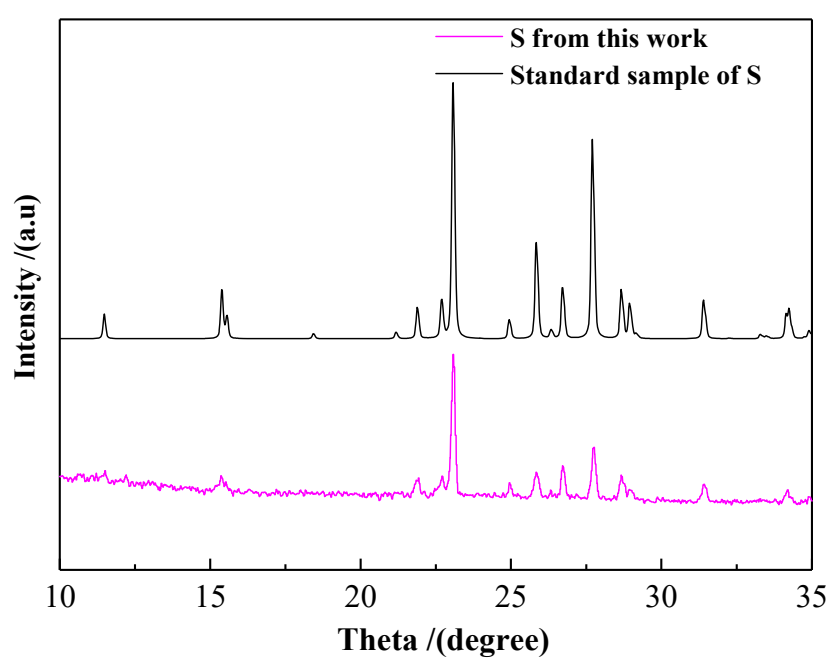

Fig. 11. XRD spectra of desulfurization products and standard rhombic sulfur.

experiment, we observed that the samples after adsorption were easy to regenerate naturally in the air. Therefore, the presence of $\mathrm{SO}_{4}{ }^{2-}$ in the samples before regeneration may be caused by the inevitable contact with air during the XPS sample preparation process. This indicates that a small part of sulfur in $\mathrm{H}_{2} \mathrm{~S}$ gas is oxidized to sulfate ions and elemental sulfur, and most combined with copper ions to form $\mathrm{Cu}_{2} \mathrm{~S}$. After regeneration, the result was shown in Fig. 12(c). The binding energy at $167.65 \mathrm{eV}$ was disappeared, that indicated that all the sulfur in $\mathrm{Cu}_{2} \mathrm{~S}$ has been oxidized to $\mathrm{S}$ and $\mathrm{SO}_{4}{ }^{2-}$. The XPS spectrum of $\mathrm{Cu}$ after adsorption was shown in Fig. 12(b). The $\mathrm{Cu}^{+}$was confirmed by the $\mathrm{Cu} 2 \mathrm{p}_{3 / 2}$ binding energy within the range of 930-937 eV without any shakeup satellite peak (Jin and Nam, 2006). It shows $\mathrm{Cu}(\mathrm{I}) 2 \mathrm{p}_{3 / 2}$ appeared at $932.9 \mathrm{eV}$ and $\mathrm{Cu}(\mathrm{I}) 2 \mathrm{p}_{1 / 2}$ appeared at $952.40 \mathrm{eV}$. It illustrates that the $\mathrm{Cu}$ in the adsorption exists in the form of $\mathrm{Cu}_{2} \mathrm{~S}$ after adsorption (Deroubaix and Marcus, 1992; Perry and Taylor, 1986). The XPS spectrum of $\mathrm{Cu}$ after regeneration was shown in Fig. 12(d). The $\mathrm{Cu}^{2+}$ was assigned to the binding energy of the XPS contribution ranging from 928 to $937 \mathrm{eV}$ with a satellite contribution in the range of 937-947 eV (Jin and Nam, 2006; Ma et al., 2019b). Compared with the state before regeneration, $\mathrm{Cu}(\mathrm{I})$ was oxidized to $\mathrm{Cu}(\mathrm{II})$ by oxygen in air. $\mathrm{Cu}(\mathrm{II}) 2 \mathrm{p}_{3 / 2}$ appears at $932.70 \mathrm{eV}$ and $\mathrm{Cu}(\mathrm{II}) 2 \mathrm{p}_{1 / 2}$ appears at $952.70 \mathrm{eV}$ in Fig. 12(d) (Perry and Taylor, 1986).

In order to study the mechanism of the reaction more clearly, the FT-IR spectrum of $\mathrm{TAECuCl}_{3}$ in the whole process was tested. The result was shown in Fig. 13. For the three curves, the broad band at $3480 \mathrm{~cm}^{-1}$ can be assigned to the existence of N-H structure. The band at $3044 \mathrm{~cm}^{-1}$ is caused by hydrogen bond vibration between $\mathrm{N}-\mathrm{H}$ bond in TAECl and $\mathrm{Cl}^{-}$in $\mathrm{CuCl}_{2}$. The broad band at $2495 \mathrm{~cm}^{-1}$ can be assigned to the C-H bond in TAE (Min et al., 2015). In addition, a new peak has emerged after the absorption of $\mathrm{H}_{2} \mathrm{~S}$ at $2355 \mathrm{~cm}^{-1}$, where the broad band can be assigned to the existence of S-H structure in $\mathrm{HS}^{-}$, this is because $\mathrm{H}_{2} \mathrm{~S}$ is adsorbed in DESs, reduces the activation energy of the reaction (Ma and Wang, 2014a; Zheng et al., 2018). This kind of DESs has been synthesized successfully. The infrared spectrum of DESs after adsorption was shown in Fig. 13. The peak at $2355 \mathrm{~cm}^{-1}$ was disappeared, means the reactivity of DESs was loses, and $\mathrm{H}_{2} \mathrm{~S}$ cannot be adsorbed by DESs. And the peak at $3044 \mathrm{~cm}^{-1}$ was reduced, because the $\mathrm{CuCl}_{2}$ in the system was converted to $\mathrm{Cu}_{2} \mathrm{~S}$, which caused the hydrogen bond to break. Moreover, in the adsorption saturated DESs, the peak of N-H bond has a red shift, which is caused by the fact that the fracture of hydrogen bond reduces the electron cloud density and activity of N-H structure, it indicates that the two components in DESs have synergistic effect through hydrogen bond (Liu et al., 2006). DESs immobilization technology was applied in the area of $\mathrm{H}_{2} \mathrm{~S}$ removal, which improves the utilization rate and unit adsorption of DESs due to the formation of the nanometer thin layer with DESs, and also reduces the usage and cost of DESs. It can be regarded as a process of fine desulfurization, and can recover elemental sulfur. The disadvantage is that the total sulfur capacity of the adsorbent is not outstanding, and some sulfur in $\mathrm{H}_{2} \mathrm{~S}$ is converted into sulfate, which is not convenient to be recovered.

\section{Adsorption Kinetics}

In order to investigate the adsorption kinetics of $\mathrm{H}_{2} \mathrm{~S}$ on SDESs, the adsorption breakthrough curve was measured in the form of a bubbling fluidized bed. Then, four equations, pseudo-first-order, pseudo-second-order, intra-particle diffusion and Bangham models, have been tested.

The pseudo-first-order equation is expressed as Eq. (4) (Bilgili, 2006):

$q_{t}=q_{e}\left[1-\exp \left(-k_{1} t\right)\right]$

where $q_{t}$ and $q_{e}$ are amounts of $\mathrm{H}_{2} \mathrm{~S}$ adsorbed $\left(\mathrm{mg} \mathrm{g}^{-1}\right)$ at time $t$ ( $\mathrm{min}$ ) and at equilibrium, respectively, and $k_{1}$ is the rate constant of adsorption $\left(\mathrm{min}^{-1}\right)$. 

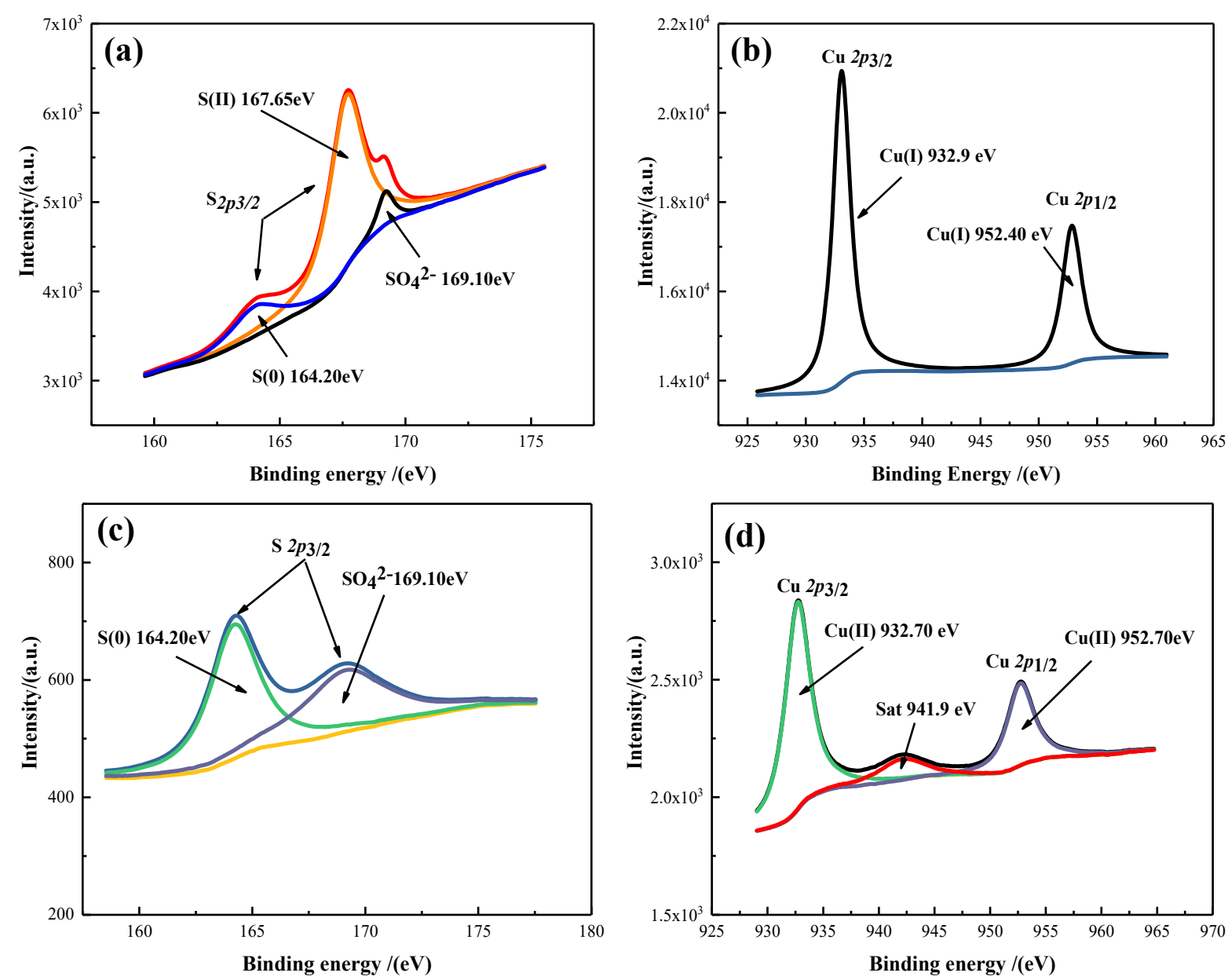

Fig. 12. XPS results for SDESs. (a) $\mathrm{S} 2 \mathrm{p}_{3 / 2}$ after adsorption until saturation, (b) $\mathrm{Cu} 2 \mathrm{p}_{3 / 2}$ and $\mathrm{Cu} 2 \mathrm{p}_{1 / 2}$ after adsorption until saturation, (c) $\mathrm{S} 2 \mathrm{p}_{3 / 2}$ after completely regeneration, and (d) $\mathrm{Cu} 2 \mathrm{p}_{3 / 2}$ and $\mathrm{Cu} 2 \mathrm{p}_{1 / 2}$ after completely regeneration. So after the first adsorption only a small amount of sulfur crystals are produced, more sulfur crystals are produced in the process of air regeneration. This prevents too much sulfur from clogging the pores during the selective oxidation process, affecting the single-adsorption effect.

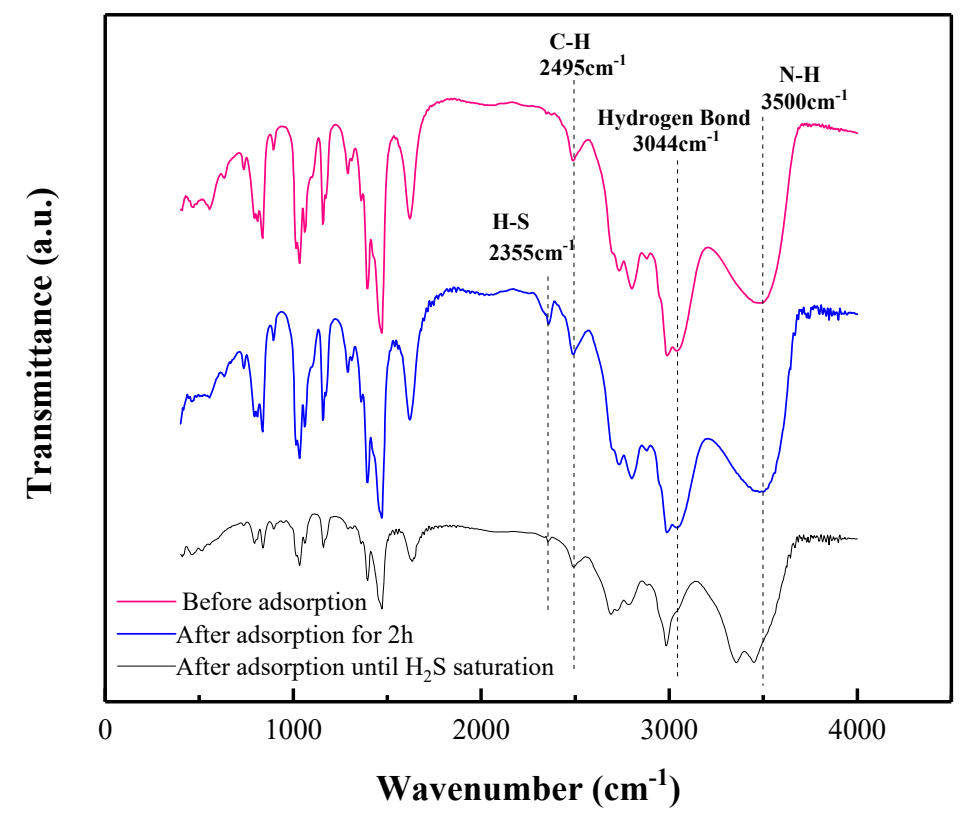

Fig. 13. FT-IR spectrum of DESs. 
The pseudo-second-order equation is expressed as Eq. (5) (Bilgili, 2006):

$q_{t}=k_{2} q_{e}^{2} t /\left(1+k_{2} q_{e} t\right)$

where $k_{2}$ is the rate constant of adsorption $\left(\mathrm{g} \mathrm{mg}^{-1} \mathrm{~min}^{-1}\right)$.

The intra-particle diffusion model can be represented as Eq. (6) (Bilgili, 2006):

$q_{t}=k_{i} t^{0.5}+C$

where $k_{i}$ is the intra-particle diffusion constant $\left(\mathrm{mg} \mathrm{g}^{-1} \mathrm{~min}^{-0.5}\right)$, and $\mathrm{C}$ is a constant $\left(\mathrm{mg} \mathrm{g}^{-1}\right)$.

The Bangham model is expressed as Eq. (7) (Bilgili, 2006):

$\log \log \left[q_{e} /\left(q_{e}-q_{t}\right)=\log \left(k_{b} / 2.303\right)+n \log t\right.$

$q_{t}$ can be written as Eq. (8): $q_{t}=q_{e}\left[1-\exp \left(-k_{b} t^{n}\right)\right]$

where $k_{b}$ is Bangham constant, and $n$ is constant.

The experimental data and nonlinear fitting of four kinetics models are shown in Fig. 14. TAECuCl 3 @FS/10 $\mathrm{wt} \%$ was used to be tested. The kinetics parameters and the correlation coefficients of models were listed in Table 4. As it can be seen, the Bangham model fit the adsorption data best, which demonstrate that the adsorption kinetics are limited by pore diffusion. DESs strengthened the adsorption of $\mathrm{H}_{2} \mathrm{~S}$ by pores and did not fundamentally change the adsorption mechanism (Bilgili, 2006).

\section{CONCLUSIONS}

In this research, a new kind of SDES desulfurizer was synthesized via the inverse supported approach and used to remove $\mathrm{H}_{2} \mathrm{~S}$. The optimum desulfurization conditions were determined to be a $10 \%$ loading of DES, an operating

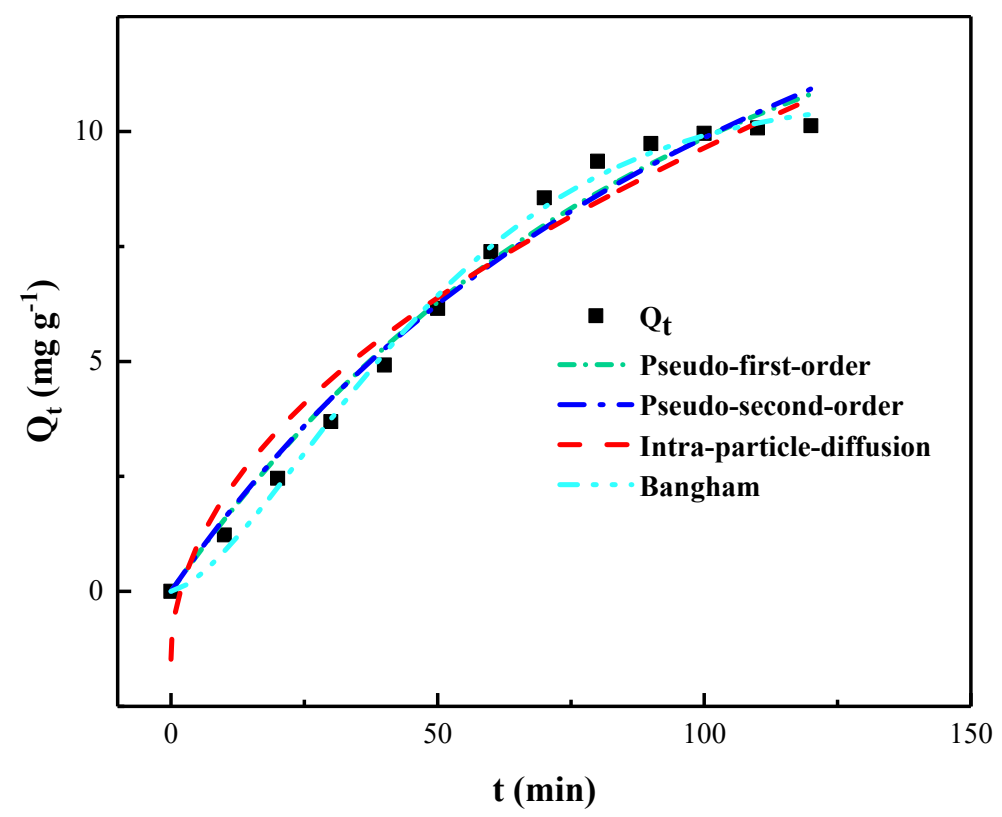

Fig. 14. Adsorption kinetics of $\mathrm{H}_{2} \mathrm{~S}$ on the optimized SDES.

Table 4. Kinetic parameters for SDESs (loading amount: $10 \mathrm{wt} \%$, gas flow rate: $100 \mathrm{~mL} \mathrm{~min}{ }^{-1}$, temperature: $30^{\circ} \mathrm{C}$ ).

\begin{tabular}{lll}
\hline Models & Parameters & Value \\
\hline Pseudo-first-order & $\mathrm{R}^{2}$ & 0.9850 \\
& $\mathrm{k}_{1}\left(\mathrm{~min}^{-1}\right)$ & $0.01131 \pm 0.00186$ \\
Pseudo-second-order & $\mathrm{q}_{\mathrm{e}}\left(\mathrm{mg} \mathrm{g}^{-1}\right)$ & $14.5545 \pm 1.43924$ \\
& $\mathrm{R}^{2}$ & 0.9823 \\
& $\mathrm{k}_{2}\left(\mathrm{~g} \mathrm{mg}^{-1} \mathrm{~min}^{-1}\right)$ & $3.06805 \mathrm{E}-4 \pm 1.170$ \\
Intra-particle diffusion & $\mathrm{q}_{\mathrm{e}}\left(\mathrm{mg} \mathrm{g}^{-1}\right)$ & $23.52797 \pm 3.45656$ \\
& $\mathrm{R}^{2}$ & 0.95276 \\
Bangham & $\mathrm{k}_{\mathrm{i}}\left(\mathrm{mg} \mathrm{g}^{-1} \mathrm{~min}^{-0.5}\right)$ & $1.11203 \pm 0.07466$ \\
& $\mathrm{C}\left(\mathrm{mg} \mathrm{g}^{-1}\right)$ & $-1.4783 \pm 0.5783$ \\
& $\mathrm{R}^{2}$ & 0.99628 \\
& $\mathrm{k}_{\mathrm{b}}\left(\mathrm{min}^{-\mathrm{n}}\right)$ & $0.00282 \pm 8.92138 \mathrm{E}$ \\
& $\mathrm{q}_{\mathrm{e}}\left(\mathrm{mg} \mathrm{g}^{-1}\right)$ & $10.76371 \pm 0.29746$ \\
$\mathrm{n}$ & $\mathrm{n}$ & $1.47712 \pm 0.08997$ \\
\hline
\end{tabular}


temperature of $30^{\circ} \mathrm{C}$, and a molar ratio of $1: 1$ for the $\mathrm{HBA}$ to the HBD. Under these conditions, the maximum breakthrough sulfur capacity was $9.97 \mathrm{mg} \mathrm{g}^{-1}$, whereas the maximum utilization rate of the DES was $86.69 \%$. Furthermore, the breakthrough sulfur capacity of the SDESs following 4 regenerations still reached $7.39 \mathrm{mg} \mathrm{g}^{-1}$. XPS and XRD analysis showed that the desulfurization products were $\mathrm{S}$ and $\mathrm{Cu}_{2} \mathrm{~S} ; \mathrm{Cu}_{2} \mathrm{~S}$ subsequently oxidized into $\mathrm{CuSO}_{4}$ and $\mathrm{S}$ during the regeneration process. The nonlinear curve fitting demonstrated that the adsorption kinetics followed those of the Bangham kinetic model. The deposition of a thin layer of DES, nano-sized in thickness, on the fumed silica enabled the highly efficient removal of $\mathrm{H}_{2} \mathrm{~S}$. Thus, SDESs can potentially be used to remove toxic gas or $\mathrm{H}_{2} \mathrm{~S}$ due to their high efficiency, high utilization rates, and economic feasibility.

\section{ACKNOWLEDGMENTS}

We acknowledge financial support from the Project of Green Manufacturing system, the Open Subject of Jiangsu Key Laboratory of Anaerobic Biotechnology (JKLAB201703 and JKLAB201605), and the Young Doctorate Cooperation Fund Project of Advanced Materials, Shandong Academy of Science (2018QNHZ04).

\section{REFERENCES}

Azizi, N. and Edrisi, M. (2017). Deep eutectic solvent immobilized on SBA-15 as a novel separable catalyst for one-pot three-component Mannich reaction. Microporous Mesoporous Mater. 240: 130-136.

Balsamo, M., Cimino, S., Falco, G. D., Erto, A. and Lisi, L. (2016). $\mathrm{ZnO}-\mathrm{CuO}$ supported on activated carbon for $\mathrm{H}_{2} \mathrm{~S}$ removal at room temperature. Chem. Eng. J. 304: 399407.

Bilgili, M.S. (2006). Adsorption of 4-chlorophenol from aqueous solutions by xad-4 resin: Isotherm, kinetic, and thermodynamic analysis. J. Hazard. Mater. 137: 157164.

Chatterjee, A., Roy, A., Chakraborty, S., Karipot, A.K., Sarkar, C., Singh, S., Ghosh, S.K., Mitra, A. and Raha, S. (2018). Biosphere atmosphere exchange of $\mathrm{CO}_{2}, \mathrm{H}_{2} \mathrm{O}$ vapour and energy during spring over a high altitude Himalayan forest in Eastern India. Aerosol Air Qual. Res. 18: 2704-2719.

Cheng, Y., Ninh, X. and Yeh, S. (2019). Dominant factors influencing the concentrations of particulate matters inside train carriages traveling in different environments in the Taipei Mass Rapid Transit System. Aerosol Air Qual. Res. 19: 1579-1592.

Dai, Y., Van, S.J., Witkamp, G.J., Verpoorte, R. and Choi, Y.H. (2013). Natural deep eutectic solvents as new potential media for green technology. Anal. Chim. Acta 766: 61-68.

de Jong, A.M., Borg, H.J., van Ijzendoorn, L.J., Soudant, V.G.F.M., de Beer, V.H.J., van Veen, J.A.R. and Niemantsverdriet, J.W. (1993). Sulfidation mechanism of molybdenum catalysts supported on a $\mathrm{SiO}_{2} / \mathrm{Si}(100)$ model support studied by surface spectroscopy. J. Phys. Chem.
97: 6477-6483.

Deroubaix, G. and Marcus, P. (1992). X-ray photoelectron spectroscopy analysis of copper and zinc oxides and sulphides. Surf. Interface Anal. 18: 39-46.

Dong, K., Zhang, S., Wang, D. and Yao, X. (2006). Hydrogen bonds in imidazolium ionic liquids. J. Phys. Chem. A 110: 9775-9782.

Dong, K. and Zhang, S. (2012). Hydrogen bonds: A structural insight into ionic liquids. Chem. Eur. J. 18: 2748-2761.

Fukumoto, K., Yoshizawa, M. and Ohno, H. (2005). Room temperature ionic liquids from 20 natural amino acids. $J$. Am. Chem. Soc. 127: 2398-2399.

Ge, K., Wu, Y., Wang, T. and Wu, J. (2019). Humidity swing adsorption of $\mathrm{H}_{2} \mathrm{~S}$ by fibrous polymeric ionic liquids (PILs). Sep. Purif. Technol. 217: 1-7.

Gorke, J.T., Srienc, F. and Kazlauskas, R.J. (2008). Hydrolase-catalyzed biotransformations in deep eutectic solvents. Chem. Commun. 10: 1235-1237.

Huang, K., Wu, Y.T. and Hu, X.B. (2016a). Effect of alkalinity on absorption capacity and selectivity of $\mathrm{SO}_{2}$ and $\mathrm{H}_{2} \mathrm{~S}$ over $\mathrm{CO}_{2}$ : Substituted benzoate-based ionic liquids as the study platform. Chem. Eng. J. 297: 265276.

Huang, K., Zhang, X.M., Hu, X.B. and Wu, Y.T. (2016b). Hydrophobic protic ionic liquids tethered with tertiary amine group for highly efficient and selective absorption of $\mathrm{H}_{2} \mathrm{~S}$ from $\mathrm{CO}_{2}$. AIChE J. 62: 4480-4490.

Huang, Y., Su, W., Wang, R. and Zhao, T. (2019). Removal of typical industrial gaseous pollutants: From carbon, zeolite, and metal-organic frameworks to moleculary imprinted adsorbents. Aerosol Air Qual. Res. 19: 21302150.

Jaiboon, V., Yoosuk, B. and Prasassarakich, P. (2014). Amine modified silica xerogel for $\mathrm{H}_{2} \mathrm{~S}$ removal at low temperature. Fuel Process. Technol. 128: 276-282.

Jin, W. C. and Nam, I. S. (2006). Characteristics of copper ion exchanged mordenite catalyst deactivated by $\mathrm{HCl}$ for the reduction of $\mathrm{NO}_{x}$ with $\mathrm{NH}_{3}$. Appl. Catal., B 64: 42-50.

Kazuya, Y., Chie, Y., Sayaka, U. and Noritaka, M. (2005). Peroxotungstate immobilized on ionic liquid-modified silica as a heterogeneous epoxidation catalyst with hydrogen peroxide. J. Am. Chem. Soc. 127: 530-531.

Kwok, K.M., Ong, S.W.D., Chen, L. and Hua, C.Z. (2017). Constrained growth of $\mathrm{MoS}_{2}$ nanosheets within a mesoporous silica shell and its effects on defect sites and catalyst stability for $\mathrm{H}_{2} \mathrm{~S}$ decomposition. ACS Catal. 8: 714-724.

Li, C., Liu, L. and Tan, W. (2019). Evaluation of RSM for simulating dispersion of $\mathrm{CO}_{2}$ cloud in flat and urban terrains. Aerosol Air Qual. Res. 19: 390-398.

Liu, C. and Maciel, G.E. (1996). The fumed silica surface: A study by NMR. J. Am. Chem. Soc. 118: 5103-5119.

Liu, X., Wang, B., Wang, D., Cheng, J., Meng, Q., Zhang, Z., Gao, P., An, J., Lou, J. and Li, M. (2019a). Study on the desulfurization performance of metal-based low transition temperature mixtures: Removal of hydrogen sulfide and sulfur recovery. Fuel Process. Technol. 193: 372-377. 
Liu, S., Ji, P., Ye, D., Qu, R., Zheng, C. and Gao, X. (2019b). Regenation of potassium poisoned catalysts for the selective catalytic reduction of $\mathrm{NO}$ with $\mathrm{NH}_{3}$. Aerosol Air Qual. Res. 19: 649-656.

Liu, X. and Wang, R. (2017). An innovative approach to oxidative removal of hydrogen sulfide using the solution of peroxo heteropolyacid. Aerosol Air Qual. Res. 17: 1341-1346.

Liu, Y., Liu, W., Li, H., Liu, J. and Yang, Y. (2006). Theoretical study of hydrogen bonding interaction in nitroxyl (HNO) dimer: Interrelationship of the two N$\mathrm{H} \cdots \mathrm{O}$ blue-shifting hydrogen bonds. J. Phys. Chem. A 110: 11760-11764.

Lungwitz, R. and Spange, S. (2008). A hydrogen bond accepting (HBA) scale for anions, including room temperature ionic liquids. New J. Chem. 32: 392-394.

Ma, Y. and Wang, R. (2014a). $\mathrm{H}_{2} \mathrm{~S}$ absorption capacity of ionic liquid-MDEA- $\mathrm{H}_{2} \mathrm{O}$ combined desulfurizers. Chem. J. Chin. Univ. 35: 1515-1522.

Ma, Y.Q. and Wang, R. (2014b). $\mathrm{H}_{2} \mathrm{~S}$ absorption capacity and regeneration performance of amine Fe-based Ionic liquid. Chem. J. Chin. Univ. 35: 760-765.

Ma, Y., Liu, X. and Wang, R. (2017). Efficient removal of $\mathrm{H}_{2} \mathrm{~S}$ at high temperature using the ionic liquid solutions of $\left[\mathrm{C}_{4} \mathrm{mim}\right]_{3} \mathrm{PMo}_{12} \mathrm{O}_{40}-\mathrm{An}$ organic polyoxometalate. $J$. Hazard. Mater. 331: 109-116.

Ma, Y., Mao, J., Xiao, C., Zhao, T. and Zang, L. (2019a). Zeolite supported ionic liquid improved by cyclodextrins for efficient removal capacity of $\mathrm{H}_{2} \mathrm{~S}$. Chem. Lett. 48: 234-237.

Ma, Y., Mao, J., Xiao, C., Li, Y. and Zang, L. (2019b). Immobilization of functionalized ionic liquid on sol-gel derived silica for efficient removal of $\mathrm{H}_{2} \mathrm{~S}$. China Pet. Proc. Petrochem. Technol. 1: 62-70.

Min, L., Jian, G., Jing, H., Liang, W., Wang, K. K., Duan, E. and Guo, B. (2015). Absorption and oxidation of $\mathrm{H}_{2} \mathrm{~S}$ in triethylamine hydrochloride ferric chloride ionic liquids. J. Mol. Liq. 209: 58-61.

Montes, D., Tocuyo, E., González, E., Rodríguez, D., Solano, R., Atencio, R., Ramos, M. A. and Moronta, A. (2013). Reactive $\mathrm{H}_{2} \mathrm{~S}$ chemisorption on mesoporous silica molecular sieve-supported $\mathrm{CuO}$ or $\mathrm{ZnO}$. Microporous Mesoporous Mater. 168: 111-120.

Nath, S. and Yadav, S. (2018). A comparative study on fog and dew water chemistry at New Delhi, India. Aerosol Air Qual. Res. 18: 26-36.

Perry, D.L. and Taylor, J.A. (1986). X-ray photoelectron and Auger spectroscopic studies of $\mathrm{Cu}_{2} \mathrm{~S}$ and CuS. J. Mater. Sci. Lett. 5: 384-386.

Shen, X., Wu, H., Cao, X., Zhang, W., Yao, Z. and Hao, X. (2018). Gaseous and carbonaceous composition of $\mathrm{PM}_{2.5}$ emitted from rural vehicles in China. Aerosol Air Qual. Res. 18: 1993-2004.

Shi, F., Zhang, Q., Li, D. and Deng, Y. (2005). Silica-gelconfined ionic liquids: A new attempt for the development of supported nanoliquid catalysis. Chem. Eur. J. 11:
5279-5288.

Smith, E.L., Abbott, A.P. and Ryder, K.S. (2014). Deep eutectic solvents (DESs) and their applications. Chem. Rev. 114: 11060-11082.

Soriano, M.D., Jimenezjimenez, J., Concepcion, P., Jimenezlopez, A., Rodriguezcastellon, E. and Jml, N. (2009). Selective oxidation of $\mathrm{H}_{2} \mathrm{~S}$ to sulfur over vanadia supported on mesoporous zirconium phosphate heterostructure. Appl. Catal., B 92: 271-279.

Sun, F., Liu, J., Chen, H., Zhang, Z., Qiao, W., Long, D. and Ling, L. (2013). Nitrogen-rich mesoporous carbons: highly efficient, regenerable metal-free catalysts for lowtemperature oxidation of $\mathrm{H}_{2} \mathrm{~S}$. ACS Catal. 3: 862-870.

Wagner, C.D. and Taylor, J.A. (1980). Generation of XPS Auger lines by bremsstrahlung. J. Electron. Spectrosc. Relat. Phenom. 20: 83-93.

Wang, B., Zhang, K., Ren, S., Hou, Y. and Wu, W. (2016). Efficient capture of low partial pressure $\mathrm{H}_{2} \mathrm{~S}$ by tetraethyl ammonium amino acid ionic liquids with absorptionpromoted solvents. RSC Adv. 6: 101462-101469.

Wang, S., Yang, D. and Zeng, R. (2018). Immiscible multiphase flow behaviours of water-oil- $\mathrm{CO}_{2}$ ternary system flooding using X-ray CT. Aerosol Air Qual. Res. 18: 1089-1101.

Wang, Y., Liu, X., Kraslawski, A., Gao, J. and Cui, P. (2019). A novel process design for $\mathrm{CO}_{2}$ capture and $\mathrm{H}_{2} \mathrm{~S}$ removal from the syngas using ionic liquid. J. Cleaner Prod. 213: 480-490.

Welton, T. (1999). Room-temperature ionic liquids. Solvents for synthesis and catalysis. Chem. Rev. 99: 2071-2084.

Widiana, D.R., Wang, Y., You, S., Yang, H., Wang, L., Tsai, J. and Chen, H. (2019). Air pollution profiles and health risk assessment of ambient volatile organic compounds above a municipal wastewater treatment plant, Taiwan. Aerosol Air Qual. Res. 19: 375-382.

Xue, W., Zeng, S., Wang, J., Shang, D., Zhang, X., Liu, J. and Zhang, Y. (2018). Selective separation of hydrogen sulfide with pyridinium-based ionic liquids. Ind. Eng. Chem. Res. 57: 1284-1293.

Yang, D., Chen, G. and Zhang, R. (2006). Estimated public health exposure to $\mathrm{H}_{2} \mathrm{~S}$ emissions from a sour gas well blowout in Kaixian County, China. Aerosol Air Qual. Res. 6: 430-443.

Yu, X.R., Liu, F., Wang, Z.Y. and Chen, Y. (1990). Auger parameters for sulfur-containing compounds using a mixed aluminum-silver excitation source. J. Electron. Spectrosc. Relat. Phenom. 50: 159-166.

Zheng, X.X., Shen, L.J., Chen, X.P., Zheng, X.H. and Jiang, L.L. (2018). Amino-modified Fe-terephthalate metalorganic framework as an efficient catalyst for the selective oxidation of $\mathrm{H}_{2} \mathrm{~S}$. Inorg. Chem. 57: 10081-10089.

Received for review, October 20, 2019 Revised, November 15, 2019 Accepted, November 16, 2019 